\title{
Cobalt(II) complexes with azole-pyridine type ligands for non-aqueous redox- flow batteries: Tunable Electrochemistry via Structural Modification
}

Craig G. Armstrong, Kathryn E. Toghill

Department of Chemistry, Lancaster University, Lancaster, United Kingdom, LA1 4YB

\section{Graphical abstract}

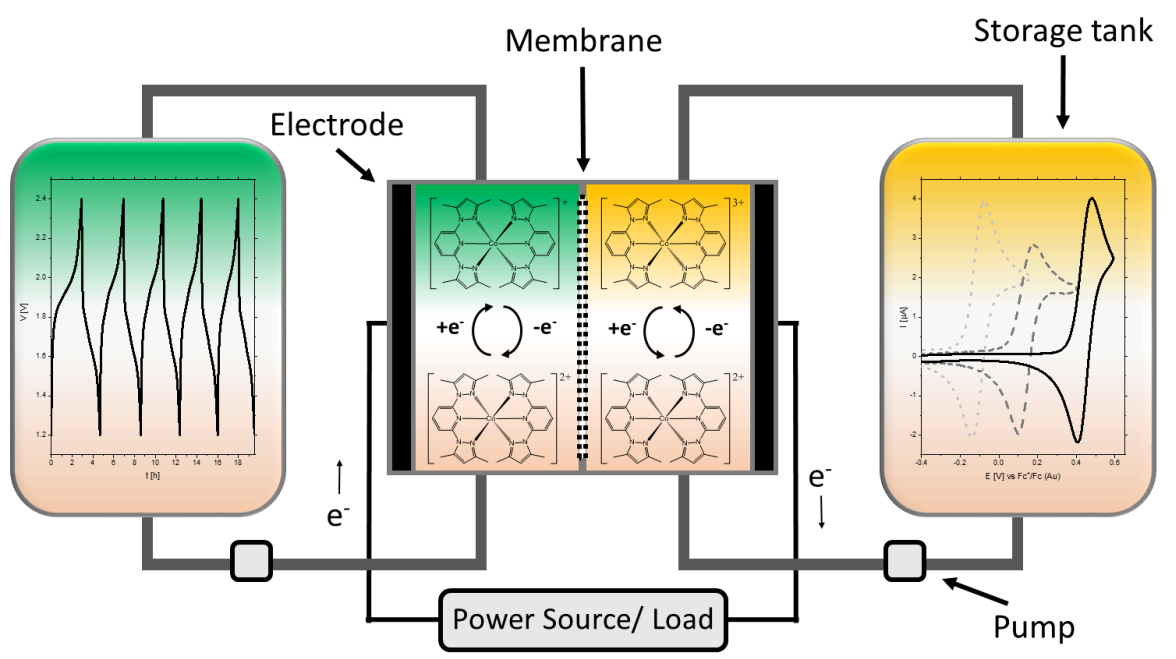

\begin{abstract}
A single species redox flow battery employing a new class of cobalt(II) complexes with 'tunable' tridentate azole-pyridine type ligands is reported.

Four structures were synthesised and their electrochemical, physical and battery characteristics were investigated as a function of successive substitution of the ligand terminal pyridyl donors. The $\mathrm{Co}(\mathrm{II} / \mathrm{I})$ and $\mathrm{Co}(\mathrm{III} / \mathrm{II})$ couples are stable and quasi-reversible on gold and glassy carbon electrodes, however redox potentials are tunable allowing the cobalt potential difference to be preferentially increased from 1.07 to $1.91 \mathrm{~V}$ via pyridine substitution with weaker $\sigma$-donating/ $\pi$-accepting 3,5 -dimethylpyrazole groups. The charge-discharge properties of the system were evaluated using an $\mathrm{H}$-type glass cell and graphite rod electrodes. The complexes delivered high Coulombic efficiencies of $89.7-99.8 \%$ and very good voltaic efficiencies of 70.3-81.0\%. Consequently, energy efficiencies are high at $63.1-80.8 \%$, marking an improvement on other similar non-aqueous systems. Modification of the ligands also improved solubility from $0.18 \mathrm{M}$ to $0.50 \mathrm{M}$ via pyridyl substitution with 3,5-dimethylpyrazole, though the low solubility of the complexes limits the overall energy capacity to between 2.58 to $12.80 \mathrm{~W} \mathrm{~h} \mathrm{~L}^{-1}$.
\end{abstract}

\section{Keywords:}

Redox flow battery; energy storage; tunable ligands; non-aqueous 


\section{Introduction}

Renewable energy resources such as wind and solar are being increasingly utilised to combat global energy demand and unsustainable overuse of polluting fossil fuels.[1] As a result, it was recently reported that renewables accounted for $25 \%$ of the UK energy production in 2016.[2] However, a current lack of large-scale energy storage in our infrastructure imposes significant limitations on their usage due to their intermittent nature and weather dependence. Redox-flow batteries (RFB) are considered a promising candidate for mitigating such limitations as well as adding versatility to our grid systems via load-levelling, peak-shaving and emergency/ back-up power.[3] Unlike conventional batteries that store energy in electrode materials, RFBs entirely store energy in liquid electrolytes that are stockpiled outside of the cell stack. As such, RFBs decouple battery power from capacity, allowing either property to be scaled independently; by increasing the number of cell stacks or the size of the storage tanks, respectively. [4]

Aqueous RFBs, such as the all-vanadium RFB (VRFB) pioneered by Skyllas-Kazacos et al.,[5-7] have achieved commercial success and have been demonstrated on a megawatt-scale. However, realisation of wide-spread application is currently hindered by their limited energy density $(\widehat{\mathrm{E}})$, which is a function of the cell potential $\left(\mathrm{V}_{\mathrm{cell}}\right)$, active-species concentration $\left(\mathrm{C}_{\mathrm{active}}\right)$ and the number of electrons transferred ( $\mathrm{n}$ ).

Given the narrow $1.23 \mathrm{~V}$ electrochemical window of water and the $<2 \mathrm{M}$ solubility of simple inorganic salts with one-electron transitions, aqueous RFBs have reached the maximum energy density that can be reasonably achieved; $<33 \mathrm{~W} \mathrm{~h} \mathrm{~L}^{-1}$.

$$
\widehat{\mathrm{E}} \approx \mathrm{nV}_{\text {cell }} \mathrm{C}_{\text {active }} \mathrm{F} / 2
$$

Non-aqueous redox-flow batteries (NA-RFBs) can in theory achieve higher energy densities than their aqueous counterparts by employing solvents which are stable over a wider potential range and redox-active species that offer larger redox potentials and multi-electron transitions.[8] Many different designs have been investigated to date utilising a wide range of new chemistries and targeted modification.[9] Most significantly, metallo-organic coordination complexes (MCCs) have featured predominantly in the literature due to their variable oxidation states which allow single-species battery designs to be produced, akin to the VRFB, in order to avoid issues with cross-contamination via membrane diffusion.[10,11] As such, the vanadium tris-acetylacetonate NA-RFB has received considerable attention due to its $2.2 \mathrm{~V}$ cell potential and reasonable $\approx 0.6 \mathrm{M}$ solubility.[12] However, due to its one-electron design, its energy density is limited by the $\left[\mathrm{V}(\mathrm{acac})_{3}\right]$ solubility.

In order for NA-RFBs to realise commercial application, their energy density must be sufficiently high to offset their capital investment; non-aqueous electrolytes are significantly more expensive than aqueous electrolytes due to the higher cost of the organic solvents and supporting electrolyte.[13] As such, the redox active species employed must fully exploit the solvent stability region, possess a high number of electron transitions and be highly soluble; in order to increase the $\mathrm{V}_{\text {cell }}, \mathrm{n}$ and $\mathrm{C}_{\text {active }}$ parameters respectively. Attempts to increase the number of stoichiometric electrons transferred has featured the use of metalloorganic electrolytes, such as chromium tris bipyridine complexes, $[14,15]$ which undergo distinctive 'noninnocent' ligand-centric redox couples in addition to those associated with the metal-centred oxidation states.[16] Whereas, studies aimed at increasing complex solubility have functionalised the backbones of simple ligand structures, such as acetylacetonate or bipyridine, with polar moieties that possess more preferential solvent interactions.[14,17] However, no studies thus far have modified the intrinsic ligand structure to customise the electrochemistry of the complex, in order to increase the cell potential.

Herein, we examine the electrochemical properties of a class of cobalt(II) complexes with azole-pyridine ligands and evaluate their applicability for a novel NA-RFB.[18,19] Such complexes contain tridentate ligands 
(bidentate structures are also possible), comprised of pyridine and azole donor groups, that have a 'tunable' design.[20] By successive substitution of pyridine donors with weaker electron-donating azole groups, their coordination chemistry can be modified resulting in significant changes in their electrochemistry. As such, the cobalt redox potentials can be 'tuned' to give larger potential differences and hence, we demonstrate the ability to increase the cell potential of a simple one-electron NA-RFB design by modification of the intrinsic ligand structure. In addition, depending on their structure, they are also capable of reversible noninnocent ligand redox couples which may be utilised to create a four-oxidation state, one-electron RFB design akin to the VRFB with an even larger cell potential. Besides their desirable electrochemical properties, they are also conveniently synthesised, allowing easy modification of their structure, and possess superior thermodynamic and kinetic stability compared to previously reported MCCs with bidentate ligands.

Furthermore, cobalt complexes generally have superb electrochemical behaviour, low toxicity and high abundance, which has resulted in their usage as redox shuttles in dye-sensitized solar cells [21-23] and as redox species in previous NA-RFB designs.[24-26]

The electrochemistry, battery performance and solubility of each complex was examined as a function of the successive substitution of the terminal-pyridine groups of $2,2^{\prime}: 6^{\prime}, 2^{\prime \prime}$-Terpyridine with either 3,5dimethylpyrazole or 1,2,4-triazole.

\section{Experimental}

\subsection{Chemicals and reagents}

All chemicals were analytical or reagent grade and used as received from the supplier without further purification. Sigma Aldrich, UK; DMSO (anhydrous, $\geq 99.9 \%$ ), $\mathrm{CoCl}_{2} \cdot 6 \mathrm{H}_{2} \mathrm{O}$ (ACS reagent, $98 \%$ ), 2,6dibromopyridine (98\%), $\mathrm{KPF}_{6}$ (98\%). TCl Europe; 1,2,4-triazole (>98.0\%), 6-bromo-2,2'-bipyridine (>97.0\%), ${ }^{\mathrm{t}} \mathrm{BuOK}(>97.0 \%), \mathrm{TBA} \mathrm{PF}_{6}(>98.0 \%)$. Fisher; $\mathrm{MeCN}$ (Lab reagent grade, $\left.>99 \%\right), \mathrm{MeOH}$ (Analytical grade, 99.99 \%). ACROS Organics; MeCN (AcroSeal ${ }^{\circledR}$, anhydrous, extra dry over molecular sieves, 99.9 \%). Fluka Analytical; 3,5-dimethylpyrazole (Produced by Wacker, $\geq 99.0 \%$ ). Alfa Aesar; $2,2^{\prime}: 6^{\prime}, 2^{\prime \prime}$-terpyridine (97\%).

\subsection{Synthesis of ligands and cobalt(II) complexes}

Complexes 1-4 were prepared by a simplified procedure based upon the method reported in [19] such that reactions were not conducted in an inert environment or purified by chromatography (Fig 1.). Ligand L1 was purchased whereas ligands L2-L5 were synthesised by non-catalysed C-N coupling of 3,5dimethylpyrazole or 1,2,4-triazole with 6-bromo-2,2'-bipyridine or 2,6-dibromopyridine in the presence of potassium tert-butoxide, in anhydrous DMSO, to give the mono- (L2 and $\mathbf{L 4}$ ) or bis-substituted (L3 and L5) azole-pyridine ligands respectively. Corresponding complexes 1-4 were produced by reaction of $\mathrm{CoCl}_{2} \cdot \mathrm{H}_{2} \mathrm{O}$ with excess of ligand L1-L4 in methanol before precipitation in $\mathrm{KPF}_{6}$ solution to give the hexafluorophosphate salt. All products were characterised by ${ }^{1} \mathrm{H}$ NMR (supporting information). 


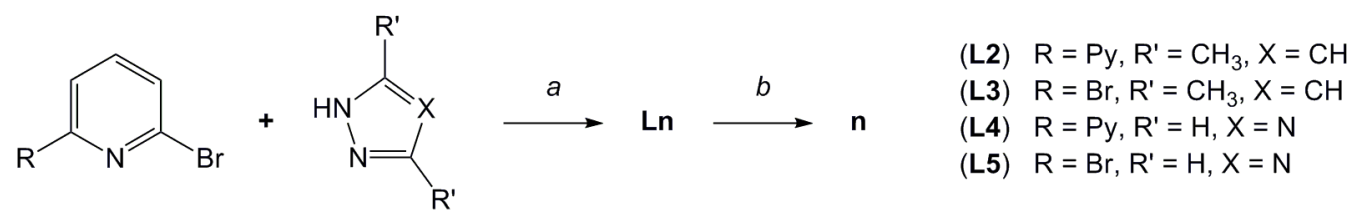<smiles>c1ccc(-c2cccc(-c3ccccn3)n2)nc1</smiles>

L1

$1=\left[\mathrm{Co}(\mathrm{L} 1)_{2}\right]\left(\mathrm{PF}_{6}\right)_{2}$<smiles>Cc1cc(C)n(-c2cccc(-c3ccccn3)n2)n1</smiles>

$2=\left[\mathrm{Co}\left(\mathrm{L}_{2}\right)_{2}\right]\left(\mathrm{PF}_{6}\right)_{2}$<smiles>c1ccc(-c2cccc(-n3cncn3)n2)nc1</smiles>

L4

$4=\left[\mathrm{Co}(\mathrm{L} 4)_{2}\right]\left(\mathrm{PF}_{6}\right)_{2}$<smiles>Cc1cc(C)n(-c2cccc(-n3nc(C)cc3C)n2)n1</smiles>

$3=\left[\mathrm{Co}(\mathrm{L} 3)_{2}\right]\left(\mathrm{PF}_{6}\right)_{2}$<smiles>c1cc(-n2cncn2)nc(-n2cncn2)c1</smiles>

L5

$\mathbf{5}=\left[\mathrm{Co}(\mathbf{L 5})_{2}\right]\left(\mathrm{PF}_{6}\right)_{2}$

Fig 1. Synthesis of ligands L1-L5 and cobalt(II) complexes 1-5: (a) anhydrous DMSO, ${ }^{\mathrm{B}} \mathrm{BuOK}, 110-140{ }^{\circ} \mathrm{C}$; (b) $\mathrm{CoCl}_{2} \cdot \mathrm{H}_{2} \mathrm{O}$, methanol, $60{ }^{\circ} \mathrm{C}, \mathrm{KPF}_{6}$.

\subsection{Cyclic voltammetry}

Cyclic voltammetry (CV) experiments were performed in deaerated $1 \mathrm{mM}$ solutions of each complex, with $0.1 \mathrm{M} \mathrm{TBA} \mathrm{PF_{6 }}$ supporting electrolyte, in hydrous acetonitrile. A three-electrode cell was employed consisting of a platinum wire auxiliary electrode, silver wire quasi-reference and either a gold or glassy-carbon (GC) disk working electrode (1.6 and $3.0 \mathrm{~mm}$ diameter respectively, BASi, Alvatek, UK). Working electrodes were polished before use with two grades of diamond slurries ( $3 \mu \mathrm{m}$ and $0.25 \mu \mathrm{m}$, Buehler) and alumina suspension $(0.05 \mu \mathrm{m}$, Buehler) prior to sonication in deionized water, methanol rinsing and drying under compressed nitrogen. The quasi-reference was stabilized by galvanostatic deposition of $\mathrm{AgPF}_{6}$ from saturated $\mathrm{KPF}_{6}$ solution and all redox potentials were reported against the ferrocene/ ferrocenium ion redox couple as an internal standard. Measurements were recorded using a PC-controlled Compactstat (IVIUM Technologies) and redox-couple reversibility was assessed as a function of increasing scan rate in the range of $10-1280 \mathrm{mV} \mathrm{s}^{-1}$.

\subsection{Charge-discharge cell cycling}

Battery cycling experiments were conducted on $1 \mathrm{mM}$ solutions of each complex in anhydrous acetonitrile with 0.5 $\mathrm{M} \mathrm{TBA} \mathrm{PF}_{6}$ electrolyte in a nitrogen glove-box (MBRAUN). A H-type glass cell was employed consisting of two graphite rod electrodes (Goodfellow Cambridge Limited, 99.997\%, $5.0 \mathrm{~mm}$ diameter, $\approx 4 \mathrm{~cm}$ separation), an anionic-exchange membrane (Fumatech, Fumasep FAP-450, $1.33 \mathrm{~cm}^{2}$ area) and a magnetic stir-bar per half-cell. Prior to assembly, the electrodes were polished with fine sand paper and tissue to give a reflective surface, whereas the membrane was soaked in the test solution for at least 24 h. Precisely $9 \mathrm{ml}$ of test solution was added to each compartment to be used as both the posolyte and negolyte during battery cycling; defined as the electrolytes that contain the redox species which are oxidised and reduced, respectively, during the charging process. The graphite rods were then immersed to give a 22.8 $\mathrm{cm}^{2}$ electroactive area. Cycling was then performed using a constant $\pm 4.4 \mu \mathrm{A} \mathrm{cm}{ }^{-2}$ current density between 
upper and lower thresholds $\approx\left(\mathrm{V}_{\text {cell }}-0.6 \mathrm{~V}\right) \leq \mathrm{V}_{\text {cell }} \leq\left(\mathrm{V}_{\text {cell }}+0.6 \mathrm{~V}\right)$; where the cell potential $\mathrm{V}_{\text {cell }}$ is defined as the potential difference between the cathodic and anodic redox couples on GC electrode.

\subsection{Solubility measurements}

The solubility of each complex in pure acetonitrile was estimated by a gradual solvent addition method. The exact mass of a small sample of complex $(\approx 10-20 \mathrm{mg})$ was initially measured using a five-decimal place balance (METTLER TOLEDO, UK). To which, $\approx 10-20 \mu \mathrm{L}$ aliquots of anhydrous MeCN were added, by use of a 2 - $200 \mu \mathrm{L}$ pipettor, until the solid dissolved by visual inspection. The total mass of solvent added was then measured and used to calculate the solvent volume, assuming a MeCN density of $0.786 \mathrm{~g} \mathrm{~cm}^{-3}$. The complex saturation concentration was then calculated and averaged over three repetitions. Mean concentrations were then reported herein to be the complex solubility.

\section{Results and discussion}

\subsection{Synthesis and characterisation}

Ligands L2-L5 and complexes 1-4 were prepared according to previous procedures. Complexes 1-2 and $\mathbf{4}$ and ligand $\mathbf{L} \mathbf{3}$ have been reported before,[18,19,23,27-29] however complex $\mathbf{3}$ and ligand $\mathbf{L} \mathbf{5}$ are new. ${ }^{1} \mathbf{H}$ NMR spectra of ligands $\mathbf{L} \mathbf{2}$ and $\mathbf{L} \mathbf{4}$ in $\mathrm{CDCl}_{3}$ gave proton signals consistent with literature,[19] whereas that of $\mathbf{L} \mathbf{3}$ and $\mathbf{L 5}$ (in $\mathrm{CDCl}_{3}$ and toluene-d8 respectively) gave proton environments with the expected signal multiplicities and integrations for the symmetrical ligand structures. ${ }^{1} \mathrm{H}$ NMR spectra of complexes 1-4 gave sharp singlets ranging from $\delta=-0.09$ to $119.00 \mathrm{ppm}$ due to the paramagnetic cobalt(II) metal centre. Chemical shifts of $\mathbf{2}$ and $\mathbf{4}$ were also consistent with literature [19] whereas $\mathbf{1}$ and $\mathbf{3}$ exhibited the expected number of proton environments.

Ligands 1-4 were all methanol-soluble white to cream solids, whereas $\mathbf{L} 5$ was significantly more insoluble and required hot DMSO, THF, toluene or benzene to solvate the non-polar structure. Complexes 1-4 were air-, light- and moisture-stable dark red to pale-brown solids, which were soluble in acetonitrile. Complex $\mathbf{5}$ could not be produced in this study despite successful synthesis of the $\mathbf{L} \mathbf{5}$ ligand and pyrazole analogues reported here and elsewhere.[18-20,28,29] It was suspected that the complexation with cobalt(II) was hindered by a combination of limiting ligand solubility, possible thermodynamic restraints such as weaker electron-deficient 1,2,4-triazole $\sigma$-donating/ $\pi$-accepting bonding and a significant kinetic barrier associated with the initial bonding of a terminal 1,2,4-triazole with the cobalt metal centre. However, we speculate that its synthesis might be possible by use of a highly activated cobalt starting material featuring weakly coordinating ligands in anhydrous inert conditions.

\subsection{Voltammetric behaviour of cobalt(II) complexes}

Cyclic voltammograms of complexes 1-4 on GC and Au electrodes (Fig 2.) exhibit reversible redox processes corresponding to metal-centric oxidation and reduction; $\mathrm{Co}(\mathrm{III} / \mathrm{II})$ and $\mathrm{Co}(\mathrm{II} / \mathrm{I})$ respectively, in addition to ligand centric reduction $L / L^{-}$at higher negative potentials. Hence, redox processes of cobalt complexes with tridentate azole-pyridine ligands can be generally attributed as:

$$
\begin{gathered}
{\left[\mathrm{Co}(\mathbf{I I})(\mathbf{L n})_{2}\right]\left(\mathrm{PF}_{6}\right)_{2} \rightleftharpoons\left[\mathrm{Co}(\mathbf{I I I})(\mathbf{L n})_{2}\right]\left(\mathrm{PF}_{6}\right)_{3}+\mathrm{e}^{-}} \\
{\left[\mathrm{Co}(\mathbf{I I})(\mathbf{L n})_{2}\right]\left(\mathrm{PF}_{6}\right)_{2}+\mathrm{e}^{-} \rightleftharpoons\left[\mathrm{Co}(\mathbf{I})(\mathbf{L n})_{2}\right]\left(\mathrm{PF}_{6}\right)} \\
{\left[\mathrm{Co}(\mathbf{I})(\mathbf{L n})_{2}\right]\left(\mathrm{PF}_{6}\right)+\mathrm{e}^{-} \rightleftharpoons\left[\mathrm{Co}(\mathbf{I})(\mathbf{L n})_{2}\right]}
\end{gathered}
$$


A NA-RFB can therefore be constructed by utilising process (2) in the posolyte and either (3) or (4) in the negolyte, to give cell potentials, $\mathrm{V}_{\text {cell }}$, in the region of 1.06 to $2.17 \mathrm{~V}$, depending on the structure of the complex and the redox couples utilised (

Table 1). Complex 2 gave the largest cell potential; $2.17 \mathrm{~V}$, when cycled between $\mathrm{Co}(\mathrm{III})$ and $\mathrm{L}^{-}$oxidation states, however complex $\mathbf{3}$ gave the largest potential difference; $1.91 \mathrm{~V}$, between the cobalt oxidation states. Utilisation of ligand redox couples would therefore yield higher cell potentials however undesirable initial electrolysis of the $\mathrm{Co}(\mathrm{II})$ electrolyte, akin to the VRFB, would be required to produce the $\mathrm{Co}(\mathrm{I})$ electrolyte.
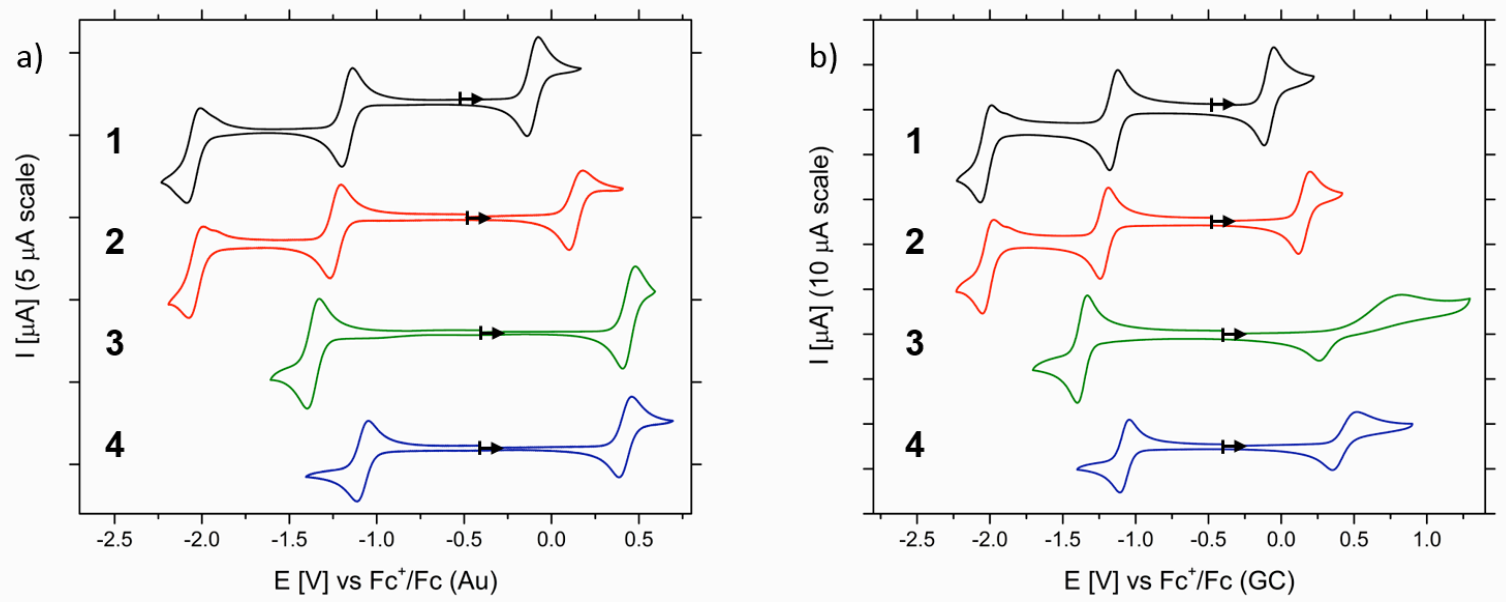

Fig 2. First clockwise cyclic voltammograms of $1 \mathrm{mM}$ cobalt(II) complexes 1-4 on a) gold and b) glassy-carbon electrode in $0.1 \mathrm{M} \mathrm{TBA} \mathrm{PF}_{6} \mathrm{MeCN}$ solution at $50 \mathrm{mV} \mathrm{s}^{-1}$. Arrows indicate the start point of cyclic voltammetry.

The electrochemical behaviour of complexes 1-4 were investigated as a function of scan rate on GC and Au electrode (Fig 3.). Properties of the complexes were found to be in agreement with literature such that redox potentials were invariant of electrode material, while reversibility was dependent; the peakseparations of $\mathrm{Co}(\mathrm{III} / \mathrm{II})$ couples were smallest on Au whereas that of $\mathrm{Co}(\mathrm{II} / \mathrm{I})$ and $\mathrm{L} / \mathrm{L}$ ' were better on $\mathrm{GC}$.[19] Reversibility ratios, defined as the ratio of the peak anodic and cathodic currents measured by baseline extrapolation, were also found to be close to unity at slow scan rates but showed general divergence with increasing scan rate, suggesting overall quasi-reversible behaviour. In addition, as observed by Shavaleev et al. [19], the reversibility of the Co(III/II) couples, for 1-4, was also found to be dependent on the electrode history such that their reproducibility was lost when the Co(II/I) couple was cycled in the same scan due to adsorbed reduced Co species.[19] As such, deposition of material on the electrode surface was visually observed after several cycles at negative potentials. Such deposition does not affect battery performance however, as the $\mathrm{Co}(\mathrm{III} / \mathrm{II})$ redox couple is never cycled on the $\mathrm{Co}(\mathrm{II} / \mathrm{I})$ compartment electrode. 


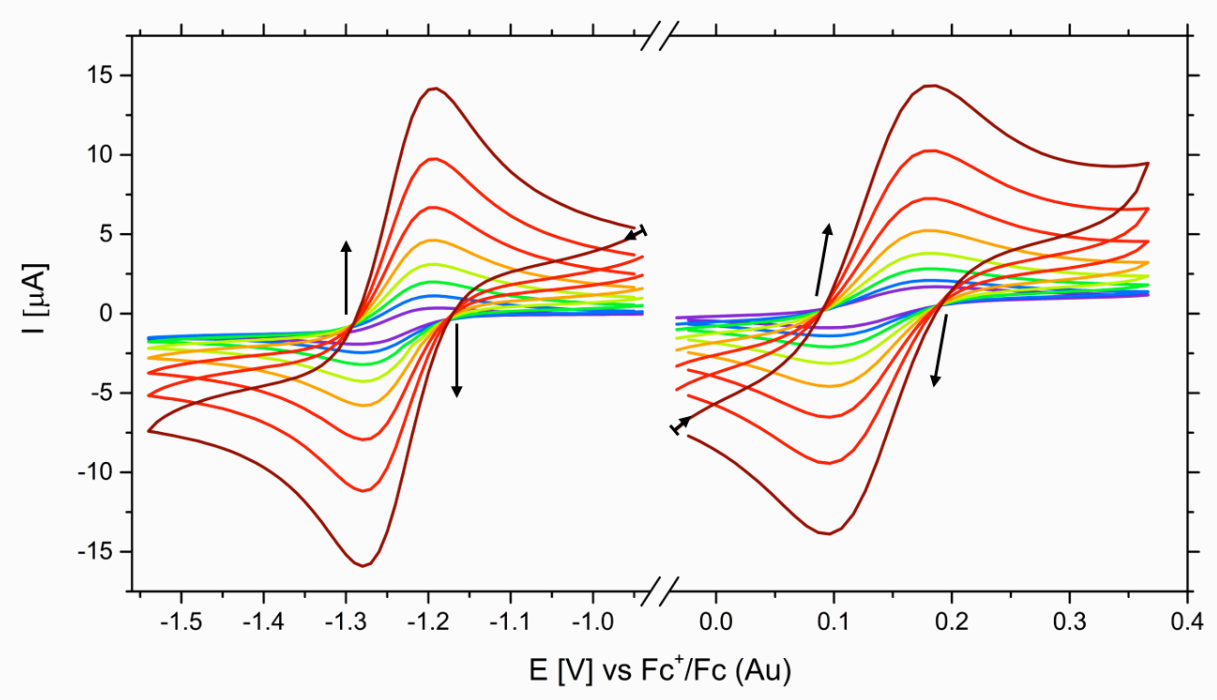

Fig 3. Second clockwise cyclic voltammograms of $1 \mathrm{mM}$ cobalt(II) complex 2 on gold electrode in $0.1 \mathrm{M}$ TBA $\mathrm{PF}_{6} \mathrm{MeCN}$ solution at scan rates in the region of $10-1280 \mathrm{mV} \mathrm{s}^{-1}$. Left) $\mathrm{Co}(\mathrm{II} / \mathrm{I})$ redox couple. Right) $\mathrm{Co}(\mathrm{III} / \mathrm{II})$ redox couple. Arrows indicate the shift of peak anodic and cathodic potentials with respect to increasing scan rate.

Complexes $\mathbf{1}$ and $\mathbf{2}$ presented with reversible ligand reductions, whereas $\mathbf{3}$ gave irreversible response and 4 completely lacked any ligand response. This behaviour suggests that the azole-pyridine ligand response originates from the reduction of the bipyridine unit,[30] however its stability is dependent on the electron deficiency of the terminal group; 1,2,4-triazole is significantly more electron deficient than pyridine, therefore it destabilises the bipyridine reduced species. Thus, azole-pyridine ligands are capable of noninnocent behaviour as long as they comprise a bipyridine unit and their terminal donor group is not significantly electron deficient.[19] Extra redox couples for cobalt complexes with bis(acetylacetone)ethylenediamine and 1,10-phenanthroline ligands have been reported but not assigned, hence it is also likely that these processes are ligand-centric reductions which result in electron delocalisation into the aromatic or conjugated ligand $\pi$-systems.[24,26,30]

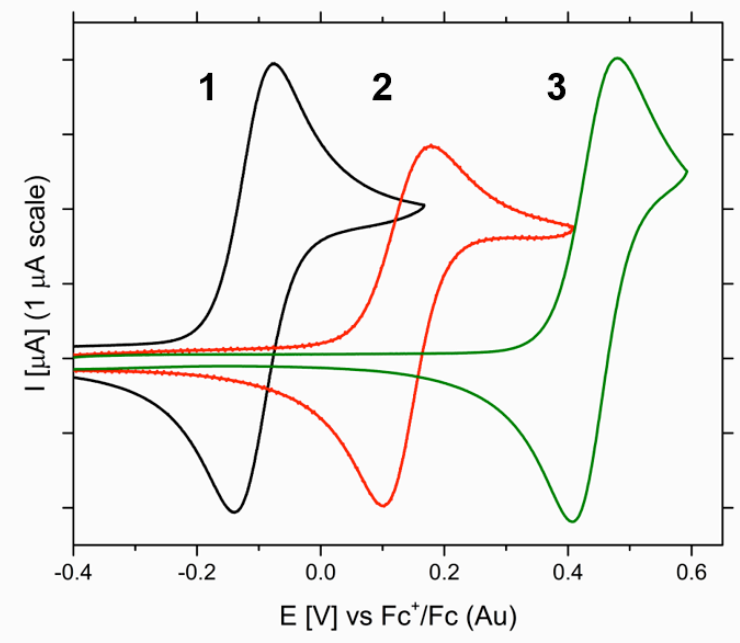

Fig 4. Overlay of the first clockwise cyclic voltammograms of the Co(III/II) redox couple, of complexes 1-3, representing the stepwise substitution of terminal $2,2^{\prime}: 6^{\prime}, 2^{\prime \prime}$-Terpyridine pyridyl groups with 3,5 - 
dimethylpyrazole donor groups. $1 \mathrm{mM}$ complex in $0.1 \mathrm{M} \mathrm{TBA} \mathrm{PF}_{6} \mathrm{MeCN}$ solution at $50 \mathrm{mV} \mathrm{s}^{-1}$ on gold electrode.

Redox potentials of the cobalt couples, (Table 1) were found to be dependent on the ligand structure and electron deficiency of its terminal azole donors, $[18,19]$ whereas ligand potentials have been shown to vary little with changes in structure.[19] Successive replacement of terminal pyridine donors with weaker $\sigma$ donating/ $\pi$-accepting 3,5-dimethylpyrazoles (in the series $1,2,3$ ) positively shifts the $\mathrm{Co}(\mathrm{III} / \mathrm{II})$ couple by approximately $275 \mathrm{mV}$ per substitution, (Fig 4 .) whereas the Co(II/I) couples are negatively shifted by $\approx 100$ $\mathrm{mV}$ (on average). In contrast, replacement with electron-deficient 1,2,4-triazole resulted in significant positive shifts of both cobalt redox couples and a dramatic loss of the $\mathrm{Co}(\mathrm{III} / \mathrm{II})$ reversibility on GC. As a result of these potential shifts, the potential difference between the cobalt redox couples also increases; from 1.07 to 1.37 to $1.91 \mathrm{~V}$ for complexes $\mathbf{1}, \mathbf{2}$ and $\mathbf{3}$ respectively (on GC). It was therefore expected that complex $\mathbf{5}$ would have produced the largest potential difference between the cobalt oxidation states, and likely the largest cell potential, as the cobalt potential difference of complex 4 was larger than that of 3; 1.51 and 1.37 $\mathrm{V}$ respectively. However, the trend of $\mathrm{Co}(\mathrm{III} / \mathrm{II})$ reversibility as a function of terminal ligand donor strength, suggests that the complex $5 \mathrm{Co}(\mathrm{III} / \mathrm{II})$ redox couple would be irreversible or at least less reversible than that of complex 3.

\section{Table 1}

Redox potentials, as measured from cyclic voltammograms at $50 \mathrm{mV} \mathrm{s}^{-1}$, of cobalt(II) complexes in $0.1 \mathrm{M}$ TBA $\mathrm{PF}_{6} \mathrm{MeCN}$ solution, reported relative to the $\mathrm{Fc}^{+} / \mathrm{Fc}$ couple. Peak separations are given in brackets and redox potentials are rounded to three significant figures.

\begin{tabular}{lllllll}
\hline Complex & Electrode & $\begin{array}{l}E_{1 / 2}^{r \theta d}[\mathrm{~V}], \\
\mathrm{L} / \mathrm{L}^{-}\end{array}$ & $\begin{array}{l}E_{1 / 2}^{r \theta d}[\mathrm{~V}], \\
\mathrm{Co}(\mathrm{II} / \mathrm{I})\end{array}$ & $\begin{array}{l}E_{1 / 2}^{o x}[\mathrm{~V}], \\
\mathrm{Co}(\mathrm{III} / \mathrm{II})\end{array}$ & $\begin{array}{l}\Delta \mathrm{E}[\mathrm{V}], \\
\mathrm{Co}(\mathrm{II}) / \mathrm{Co}(\mathrm{III}) / / \\
\mathrm{L} / \mathrm{L}^{-}\end{array}$ & $\begin{array}{l}\Delta \mathrm{E}[\mathrm{V}], \\
\mathrm{Co}(\mathrm{II}) / \mathrm{Co}(\mathrm{III}) / / \\
\mathrm{Co}(\mathrm{II}) / \mathrm{Co}(\mathrm{I})\end{array}$ \\
\hline $\mathbf{1}$ & $\mathrm{GC}$ & $-2.03(79)$ & $-1.15(57)$ & $-0.09(63)$ & 1.94 & 1.07 \\
& $\mathrm{Au}$ & $-2.05(77)$ & $-1.17(59)$ & $-0.11(64)$ & 1.94 & 1.06 \\
$\mathbf{2}$ & & & & & & 1.37 \\
& $\mathrm{GC}$ & $-2.01(78)$ & $-1.22(55)$ & $0.16(79)$ & 2.17 & 1.38 \\
$\mathbf{3}$ & $\mathrm{Au}$ & $-2.03(83)$ & $-1.24(61)$ & $0.14(77)$ & 2.17 & 1.91 \\
& & & & & & 1.81 \\
& $\mathrm{GC}$ & & $-1.37(69)$ & $0.54(566)$ & & 1.51 \\
& $\mathrm{Au}$ & & $-1.37(68)$ & $0.44(74)$ & & 1.50 \\
\hline
\end{tabular}

\subsection{Charge-discharge performance}

Charge discharge performance of complexes 1-4 in a H-type glass cell was evaluated using $1 \mathrm{mM}, 0.5 \mathrm{M}$ $\mathrm{TBA} \mathrm{PF}_{6}$ electrolyte. Due to the limiting electrode-area of a $\mathrm{H}$-type glass cell design, a constant $\pm 4.4 \mu \mathrm{A} \mathrm{cm}^{-2}$ current density was chosen. This was decided to be a suitable compromise between long cycling timescales, which are directly proportional to the current, and cell overpotentials, which arise from the reaction kinetics and high cell resistances (organic electrolyte, inter-electrode separation and the membrane). 

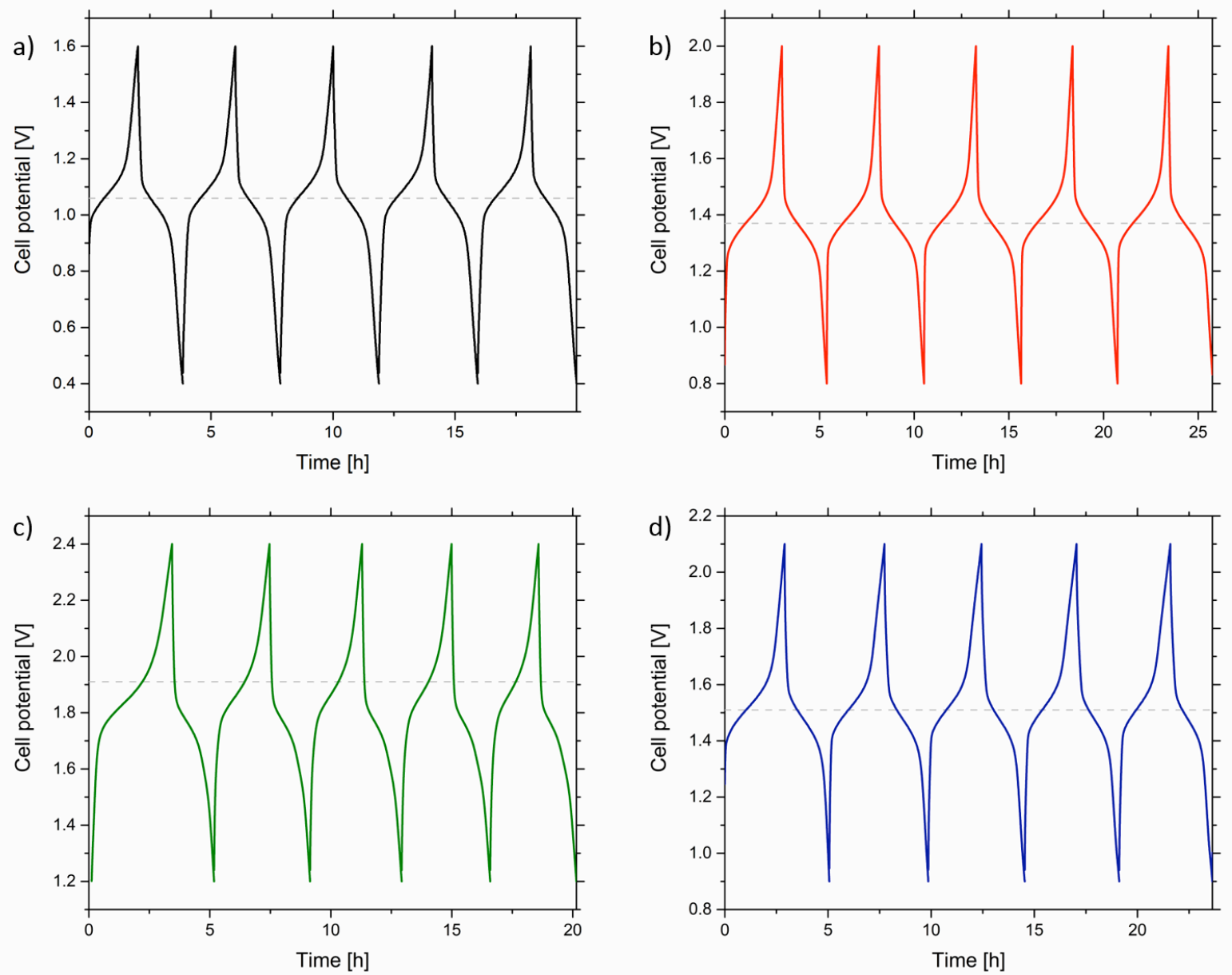

Fig 5. First five (of ten) charge-discharge cycles of $1 \mathrm{mM}$ complexes in $0.5 \mathrm{TBA} \mathrm{PF}_{6} \mathrm{MeCN}$ solution at $\pm 4.4 \mu \mathrm{A}$ $\mathrm{cm}^{-2}$. Horizontal dashed grey lines represent the theoretical cell potential, as given by CV on GC electrode. a) complex 1; $1.07 \mathrm{~V}$ theoretical cell potential, 1.6 and $0.4 \mathrm{~V}$ upper and lower thresholds. b) complex 2; $1.37 \mathrm{~V}$ theoretical cell potential, 2.0 and $0.8 \mathrm{~V}$ upper and lower thresholds. c) complex 3; $1.91 \mathrm{~V}$ theoretical cell potential, 2.4 and $1.2 \mathrm{~V}$ upper and lower thresholds. d) complex 4; $1.51 \mathrm{~V}$ theoretical cell potential, 2.1 and $0.9 \mathrm{~V}$ upper and lower thresholds.

Each complex was cycled 10 times between upper and lower thresholds which were approximately symmetric about the theoretical cell potential (given by CV on GC electrode, Table 1). Optimised thresholds were chosen to be sufficiently over/ under the cell potential to allow complete charge/ discharge, but not too large as to avoid charge transfer to unwanted processes such as ligand reduction.

Cycling of complexes gave approximately linearly increasing plateau regions, characteristic of solutionphase kinetics-limited electron transfer, and steep potential regions indicative of mass-transport limited electrolysis (Fig 5.). This is more evident in the figures presented in the SI (Fig. S13-32) in which the charge and discharge cycles are overlaid. Plateau regions were consistent with the theoretical cell potentials such that they resided within the potential range of the charge plateaus, suggesting that very little overpotential was required to charge the electrolytes. However, plateau regions for complex $\mathbf{3}$ were more consistent with the theoretical cell potential given by Au electrode due to the unusual voltammetric behaviour observed on GC (Fig 2.).

In addition to the observed charge plateaus, charge and discharge times for cell cycling (Table 2) were comparable in magnitude and also consistent with the projected electrolysis time of $2.41 \mathrm{~h}$ (calculated from Faraday's law of electrolysis, assuming constant current and a single electron transfer) suggesting that 
states-of-charge close to 0 and $100 \%$ were achieved during cycling. Visual inspection of the electrolyte colours was also consistent with the observed electrochemical measurements; battery cycling gave yellow Co(III) posolytes and red or green Co(I) negolytes for complexes 1 and 2-4 respectively.

Battery cycling performance was evaluated in terms of the coulombic, voltaic and energy efficiencies as a function of cycle number. Efficiencies were typically found to vary little with respect to cycle number without any observed capacity fade, however a gradual efficiency rise was observed for complex 4 , suggesting that the system required more time to reach equilibration (Fig 6.). Generally, all four complexes gave comparable performance (Table 2) such that mean coulombic efficiencies at lowest $89.7 \%$ and voltaic efficiencies in the range of $70.3-81.0 \%$ were achieved. Despite this, a lower energy efficiency of $63.1 \%$ was observed for complex 3 which resulted from significantly more overpotential during charging and discharging, compared to the other complexes. This overpotential most likely resulted from the poor reversibility of the $\mathrm{Co}(\mathrm{III} / \mathrm{II})$ redox couple which was observed on GC electrode, suggesting slow electron-transfer kinetics.

In general, observations suggest that changes in ligand structure, and associated electrochemistry, have little effect on battery performance at low current densities. However, it is likely that complexes $\mathbf{3}$ and $\mathbf{4}$ would have performed worse at higher charge/ discharge rates due to the slower Co(III/II) kinetics on graphite electrode. Adoption of such a low current density is not necessarily undesirable as overpotential and efficiency loss may be mitigated by use of high surface-area graphite felt electrodes in a flow-cell design. Furthermore, previous cycling experiments in the literature have demonstrated poor battery response by attempting to use too large current densities, resulting in larger overpotentials and requiring significantly different (and often much lower) discharge currents to discharge the cell.[24-26]

\section{Table 2}

Battery cycling performance parameters, averaged over last nine (of ten) cycles, of $1 \mathrm{mM}$ complexes in $0.5 \mathrm{M}$ TBA $\mathrm{PF}_{6} \mathrm{MeCN}_{\text {solution at } \pm 4.4 \mu \mathrm{A} \mathrm{cm}}{ }^{-2}$. Mean discharge times are given in brackets.

\begin{tabular}{lllll}
\hline Complex & $\begin{array}{l}\text { Charge } \\
\text { time }[\mathrm{h}]\end{array}$ & $\eta \mathrm{C}[\%]$ & $\eta \mathrm{V}[\%]$ & $\eta \mathrm{F}[\%]$ \\
\hline $\mathbf{1}$ & $2.14(2.03)$ & 95.2 & 76.8 & 73.0 \\
$\mathbf{2}$ & $2.84(2.84)$ & 99.8 & 81.0 & 80.8 \\
$\mathbf{3}$ & $2.84(2.55)$ & 89.7 & 70.3 & 63.1 \\
$\mathbf{4}$ & $2.90(2.73)$ & 94.2 & 77.0 & 72.5 \\
& & & & \\
\hline
\end{tabular}




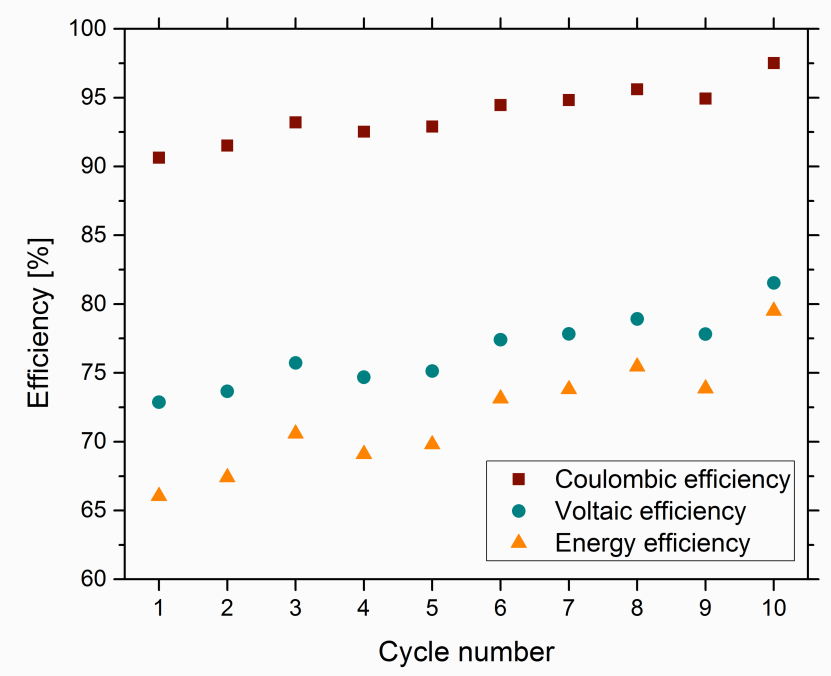

Fig 6. Battery performance as a function of cycle number of $1 \mathrm{mM}$ complex 4 in $0.5 \mathrm{TBA} \mathrm{PF}_{6} \mathrm{MeCN}$ solution at $\pm 4.4 \mu \mathrm{A} \mathrm{cm}^{-2}$. Squares - coulombic efficiency, circles - voltaic efficiency, triangles - energy efficiency.

\subsection{Complex Solubility}

The solubilities of complexes 1-4 were roughly measured by a solvent addition method. Measurements gave solubilities of $\approx 0.18,0.22,0.50$ and $0.16 \mathrm{~mol} \mathrm{dm}^{-3}$ for complexes 1-4 respectively.

Comparatively low solubilities were expected due to the non-polar nature of the ligands and their tridentate structure. As such, measured values were found to be of similar magnitude, however a $0.34 \mathrm{M}$ variation was observed due to structural differences of the ligands. Solubility of complexes in the series 1, 2, 3 increased with the number of substituted 3,5-dimethylpyrazole groups (from 0 to 2 to 4 ) due to more favourable interactions between the ligand methyl groups and the polar MeCN solvent. In contrast, substitution with 1,2,4-triazoles resulted in a loss of ligand polarity and complex solubility. We therefore speculate that complex $\mathbf{5}$ would have been the least soluble in this study making its use undesirable, despite the expected largest cell potential.

Corresponding theoretical energy densities for complexes 1-4 were calculated to be 2.58, 4.03, 12.80 and $3.24 \mathrm{~W} \mathrm{~h} \mathrm{~L}^{-1}$ by use of equation (1) and the theoretical cell potentials on $\mathrm{GC}$ electrode. The highest theoretical energy density was achieved by complex $\mathbf{3}$ due to a combination of its higher cell potential and superior solubility. Hence, full substitution with 3,5-dimethylpyrazoles resulted in a five-fold increase of energy density compared to the initial $2,2^{\prime}: 6^{\prime}, 2^{\prime \prime}$-terpyridine complex.

\section{Conclusions}

A new class of cobalt(II) complexes with 'tunable' tridentate azole-pyridine type ligands were evaluated for use as redox species in a novel non-aqueous redox-flow battery. For which, four different structures were synthesised and their electrochemical, physical and battery properties were investigated as a function of successive substitution of the terminal pyridyl groups of $2,2^{\prime}: 6^{\prime}, 2^{\prime \prime}$-terpyridine with 3,5-dimethylpyrazoles or 1,2,4-triazoles.

Cyclic voltammetry of $1 \mathrm{mM}$ complexes in $0.1 \mathrm{M} \mathrm{TBA} \mathrm{PF}_{6} \mathrm{MeCN}$ electrolyte on glassy-carbon and gold electrodes showed that such complexes undergo reversible $\mathrm{Co}(\mathrm{III} / \mathrm{II})$ and $\mathrm{Co}(\mathrm{II} / \mathrm{I})$ redox couples as well as possible non-innocent ligand redox couples (structure dependent), allowing a single-species RFB to be 
created. Redox potentials were found to be tunable, allowing the theoretical RFB cell potential to be preferentially increased from 1.07 to $1.91 \mathrm{~V}$, via pyridine substitution with weaker $\sigma$-donating/ $\pi$-accepting 3,5-dimethylpyrazole groups. In correlation, solubility was also increased from 0.18 to $0.50 \mathrm{M}$ due to more favourable polar methyl interactions with the MeCN solvent, and as result, the theoretical energy density of $2,2^{\prime}: 6^{\prime}, 2^{\prime \prime}$-terpyridinecobalt(II) hexafluorophosphate was five-fold increased from 2.58 to $12.80 \mathrm{~W} \mathrm{~h} \mathrm{~L}^{-1}$ for that of 2,6-bis-(N-3,5-dimethylpyrazoyl)pyridinecobalt(II) hexafluorophosphate.

Battery cycling experiments on $1 \mathrm{mM}$ complexes in $0.5 \mathrm{M} \mathrm{TBA} \mathrm{PF}_{6} \mathrm{MeCN}$ electrolyte, as both posolyte and negolyte, in a $\mathrm{H}$-type glass cell gave high coulombic and energy efficiencies of $89.7-99.8 \%$ and $63.1-80.8$ $\%$ respectively. Despite a small loss in energy efficiency, the experiments show that the energy density of the complexes could be increased without severe loss of battery performance.

In conclusion, Cobalt(II) complexes with azole-pyridine ligands are promising candidates for large-scale energy storage due to their tunable design, high battery performance, sustainable constituents, and minimal environmental impact. Furthermore, due to their modular structure and convenient synthesis, they are easy to produce and modify allowing direct control over battery-critical parameters such as cell potential and solubility.

\section{Acknowledgements}

The authors would like to thank Dr Mike Coogan for useful advice and support during the synthesis of the complexes.

This research did not receive any specific grant from funding agencies in the public, commercial, or notfor-profit sectors.

\section{Appendix A. Supplementary data}

NMR data (Fig. S1-8.). Scan rate cyclic voltammograms (Fig. S9-12). Battery charge-discharge cycles and efficiencies (Fig. S13-32). Supplementary data associated with this article can be found, in the online version, at

\section{References}

[1] J. Cho, S. Jeong, Y. Kim, Commercial and research battery technologies for electrical energy storage applications, Prog. Energy Combust. Sci. 48 (2015) 84.

[2] E.\& I.S. Department for Business, National Statistics Energy Trends: renewables, (2016). https://www.gov.uk/government/statistics/energy-trends-section-6-renewables (accessed November 29, 2016).

[3] Q. Huang, Q. Wang, Next-Generation, High-Energy-Density Redox Flow Batteries, Chempluschem. 80 (2015) 312-322.

[4] M.H. Chakrabarti, S. a. Hajimolana, F.S. Mjalli, M. Saleem, I. Mustafa, Redox Flow Battery for Energy Storage, Arab. J. Sci. Eng. 38 (2013) 723-739.

[5] M. Skyllas-Kazacos, M. Rychcik, R.G. Robins, A.G. Fane, New All-Vanadium Redox Flow Cell, J. Electrochem. Soc. Accelerate (1986) 1057-1058.

[6] M. Skyllas-Kazacos, F. Grossmith, Efficient vanadium redox flow cell, J. Electrochem. Soc. (1987) 2950-2953. 
[7] M. Rychcik, M. Skyllas-Kazacos, Characteristics of a new all-vanadium redox flow battery, J. Power Sources. 22 (1988) 59-67.

[8] Y. Huang, S. Gu, Y. Yan, S.F.Y. Li, Nonaqueous redox-flow batteries: features, challenges, and prospects, Curr. Opin. Chem. Eng. 8 (2015) 105-113.

[9] J. Noack, N. Roznyatovskaya, T. Herr, P. Fischer, The Chemistry of Redox-Flow Batteries, Angew. Chemie Int. Ed. 54 (2015) 9776-9809.

[10] Y. Matsuda, K. Tanaka, M. Okada, Y. Takasu, M. Morita, T. Matsumura-Inoue, A rechargeable redox battery utilizing ruthenium complexes with non-aqueous organic electrolyte, J. Appl. Electrochem. 18 (1988) 909-914.

[11] Q. Liu, A.A. Shinkle, Y. Li, C.W. Monroe, L.T. Thompson, A.E.S. Sleightholme, Non-aqueous chromium acetylacetonate electrolyte for redox flow batteries, Electrochem. Commun. 12 (2010) 1634-1637.

[12] Q. Liu, A.E.S.S. Sleightholme, A.A. Shinkle, Y. Li, L.T. Thompson, Non-aqueous vanadium acetylacetonate electrolyte for redox flow batteries, Electrochem. Commun. 11 (2009) 2312-2315.

[13] R.M. Darling, K.G. Gallagher, J.A. Kowalski, S. Ha, F.R. Brushett, Pathways to low-cost electrochemical energy storage: a comparison of aqueous and nonaqueous flow batteries, Energy Environ. Sci. 7 (2014) 3459-3477.

[14] P.J. Cabrera, X. Yang, J.A. Suttil, R.E.M. Brooner, L.T. Thompson, M.S. Sanford, Evaluation of TrisBipyridine Chromium Complexes for Flow Battery Applications: Impact of Bipyridine Ligand Structure on Solubility and Electrochemistry, Inorg. Chem. 54 (2015) 10214-10223.

[15] P.J. Cabrera, X. Yang, J.A. Suttil, K.L. Hawthorne, R.E.M. Brooner, M.S. Sanford, et al., Complexes Containing Redox Noninnocent Ligands for Symmetric, Multielectron Transfer Nonaqueous Redox Flow Batteries, J. Phys. Chem. C. 119 (2015) 15882-15889.

[16] P.J. Cappillino, H.D. Pratt, N.S. Hudak, N.C. Tomson, T.M. Anderson, M.R. Anstey, Application of Redox Non-Innocent Ligands to Non-Aqueous Flow Battery Electrolytes, Adv. Energy Mater. 4 (2014) 1300566.

[17] J.A. Suttil, J.F. Kucharyson, I.L. Escalante-Garcia, P.J. Cabrera, B.R. James, R.F. Savinell, et al., Metal acetylacetonate complexes for high energy density non-aqueous redox flow batteries, J. Mater. Chem. A. 3 (2015) 7929-7938.

[18] T. Ayers, S. Scott, J. Goins, N. Caylor, D. Hathcock, S.J. Slattery, et al., Redox and spin state control of Co (II) and Fe (II) N-heterocyclic complexes, Inorganica Chim. Acta. 307 (2000) 7-12.

[19] N.M. Shavaleev, F. Kessler, M. Grätzel, M.K. Nazeeruddin, Redox properties of cobalt(II) complexes with azole-pyridines, Inorganica Chim. Acta. 407 (2013) 261-268.

[20] N.T. Ligands, A.J. Downard, G.E. Honey, P.J. Steel, Synthesis, Spectroscopy, and Electrochemistry of Ruthenium ( 11 ) Complexes of, Inorg. Chem. 30 (1991) 3733-3737.

[21] S.M. Feldt, E.A. Gibson, E. Gabrielsson, L. Sun, G. Boschloo, A. Hagfeldt, Design of organic dyes and cobalt polypyridine redox mediators for high-efficiency dye-sensitized solar cells, J. Am. Chem. Soc. 132 (2010) 16714-16724.

[22] E. Mosconi, J.H. Yum, F. Kessler, C.J.G. Garcia, C. Zuccaccia, A. Cinti, et al., Cobalt Electrolyte/Dye Interactions in Dye-Sensitized Solar Cells: A Combined Computational and Experimental Study, J Am Chem Soc. 134 (2012) 19438-19453.

[23] Y.-W.D. Chen, Solution Redox Couples for Electrochemical Energy Storage, J. Electrochem. Soc. 128 (1981) 1460. 
[24] D. Zhang, H. Lan, Y. Li, The application of a non-aqueous bis(acetylacetone)ethylenediamine cobalt electrolyte in redox flow battery, J. Power Sources. 217 (2012) 199-203.

[25] X. Xing, D. Zhang, Y. Li, A non-aqueous all-cobalt redox flow battery using 1,10phenanthrolinecobalt(II) hexafluorophosphate as active species, J. Power Sources. 279 (2015) 205209.

[26] X. Xing, Y. Zhao, Y. Li, A non-aqueous redox flow battery based on tris(1,10-phenanthroline) complexes of iron(II) and cobalt(II), J. Power Sources. 293 (2015) 778-783.

[27] S. Hayami, Y. Komatsu, T. Shimizu, H. Kamihata, Y.H. Lee, Spin-crossover in cobalt(II) compounds containing terpyridine and its derivatives, Coord. Chem. Rev. 255 (2011) 1981-1990.

[28] D.L. Jameson, K. a Goldsby, 2,6-Bis(N-Pyrazolyl)Pyridines - the Convenient Synthesis of a Family of Planar Tridentate N3 Ligands That Are Terpyridine Analogs, J. Org. Chem. 55 (1990) 4992-4994.

[29] M.A.M. Garcia, A. Gelling, D.R. Noble, K.G. Orrell, A.G. Osborne, V. Sik, Fluxional Rhenium(I) Tricarbonyl Halide Complexes of Substituted Pyrazolpyridine Ligands. Nuclear Magnetic Resonance Studies of 1,4 Metallotropic Shifts, Polyhedron. 15 (1996) 371-379.

[30] S.A. Richert, P.K.S. Tsang, D.T. Sawyer, Ligand-centered redox processes for manganese, iron and cobalt, MnL3, FeL3, and CoL3, complexes ( $\mathrm{L}=$ acetylacetonate, 8-quinolinate, picolinate, 2,2'bipyridyl, 1,10-phenanthroline) and for their tetrakis(2,6-dichlorophenyl)porphinato complexes [M(Por)], Inorg. Chem. 28 (1989) 2471-2475. 